Revue des patrimoines

16 | 2011

Le patrimoine militaire et la question urbaine

\title{
Témoignages religieux de la Grande Guerre
}

\section{Claude Aliquot}

\section{OpenEdition}

Journals

Édition électronique

URL : http://journals.openedition.org/insitu/1273

DOI : 10.4000/insitu. 1273

ISSN : 1630-7305

\section{Éditeur}

Ministère de la culture

\section{Référence électronique}

Claude Aliquot, «Témoignages religieux de la Grande Guerre », In Situ [En ligne], 16 | 2011, mis en ligne le 30 janvier 2012, consulté le 30 avril 2019. URL : http://journals.openedition.org/insitu/1273 ; DOI : 10.4000/insitu. 1273

Ce document a été généré automatiquement le 30 avril 2019.

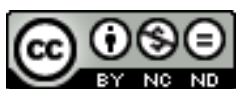

In Situ Revues des patrimoines est mis à disposition selon les termes de la licence Creative Commons Attribution - Pas d'Utilisation Commerciale - Pas de Modification 4.0 International. 


\title{
Témoignages religieux de la Grande Guerre
}

\author{
Claude Aliquot
}

1 Dans le département de l'Ariège, parmi les objets retenus récemment pour une protection au titre des Monuments historiques, deux ensembles relativement rares ont été remarqués :

2 - une chapelle d'aumônier militaire,

3 - une valise de prêtre soldat.

\section{Origine de ces ensembles}

4 Ces ensembles ont deux origines :

5 - le Service de l'Intendance des armées,

6 - l'association : «L'œuvre des campagnes ».

\section{Chapelle d'aumônier militaire}

7 En ce début du XXe siècle, les relations entre l'Église catholique et le Gouvernement français sont tendues, en raison des dispositions législatives ayant trait aux libertés religieuses :

$8 \quad-$ loi du $1^{\text {er }}$ juillet 1901 sur les associations, soumettant les congrégations religieuses à une reconnaissance légale rendue sur avis conforme du Conseil d'État et supprimant ainsi deux mille institutions religieuses d'enseignement et nombre d'établissements conventuels ;

9 - loi du 9 décembre 1905 sur la séparation des Églises et de l'État, transférant aux communes et aux départements la propriété des biens immobiliers et mobiliers de l'église de France. 
10 Toutefois, malgré la rupture des relations diplomatiques entre le Saint-Siège et l'État Français, le Ministère de la Guerre continue d'approvisionner des chapelles d'aumônier militaire pour les besoins de ses troupes. Par décret du 5 mai 1913, il prévoit une centaine d'aumôniers militaires. Un appel aux "volontaires» est lancé par Albert de MUN, fondateur de l'œuvre des aumôniers militaires, et une circulaire du ministère de la Guerre du 12 novembre 1914 porte ce nombre à 305. En réalité, ce sont près de 800 aumôniers qui seront nommés au cours de ce conflit ${ }^{1}$.

\section{Valise de prêtre soldat}

11 Lors de la mobilisation générale du $1^{\mathrm{er}}$ août 1914, séminaristes, prêtres et religieux sont mobilisés en application de la loi du 21 mars 1905, dite « des curés sacs au dos », loi qui a supprimé toutes les dispenses de service militaire, et du rescrit de 1912 levant l'irrégularité canonique encourue lorsqu'ils portent les armes.

12 Il se trouve que les prêtres, non aumôniers militaires, ne disposaient pas d'ensembles de célébrations du Saint-Sacrifice de la Messe. La fraternité instaurée dans les tranchées entre les «cléricaux » et les « anticléricaux » apaise les esprits partisans et à partir de la fin 1915 des valises de prêtre soldat sont fournies par une institution catholique dans le but de favoriser le retour de la foi dans les paroisses rurales : L'œuvre des campagnes.

13 Fondée en 1857 dans la commune de Fleury-en-Bière (Seine-et-Marne) par l'abbé JeanMarie Vandel et la comtesse Auguste de La Rochejaquelein, cette association avait pour vocation d'aider les prêtres soldats à supporter l'âpreté et la rudesse de la vie militaire et leur permettre dans ces conditions de continuer à célébrer la messe.

14 C'est l'état d'esprit relevé dans le Bulletin de l'ÆEuvre de Janvier $1915^{2}:$ «Ils sont des milliers sur le front, qui n'ont même pas la consolation, dans les intervalles d'un service toujours pénible, toujours périlleux, de pouvoir offrir le Saint-Sacrifice, parce qu'ils manquent de tout ce qui est nécessaire pour dire la messe; ils sont des milliers qui sont privés de faire la charité. Donnons-leur pour qu'ils puissent donner. Envoyons-leur de généreuses offrandes, des vêtements chauds. »

15 Deux types de colis sont ainsi constitués :

16 - les premiers, essentiellement religieux, comprennent le nécessaire pour célébrer l'office divin: vases sacrés, vêtements liturgiques, missels et objets de vénération populaire: (crucifix, chapelets, médailles, ouvrages de piété...)

17 - les seconds, plus matérialistes, sont adaptés aux circonstances de la guerre de tranchées; ils contiennent des vêtements de dessous (chemises, gilets et ceintures de flanelle...), des vêtements chauds (chandails, cache nez, passe montagne, mitaines...), des vêtements imperméables (capuchons, bottes,...) et quelques produits de coopérative (pipes, briquets, cigarettes, savon, chocolat, confitures, conserves....).

18 Jusqu'en 1915, soixante-dix autels portatifs ont été livrés. À partir de cette date, l'œuvre laisse à l'Association de Notre-Dame de Salut la charge d'approvisionner ces autels ${ }^{3}$.

\section{Composition des nécessaires de célébration}

19 Les ensembles qui nous sont parvenus ne sont malheureusement pas complets. (fig. $\mathbf{n}^{\circ} \mathbf{1}$ ) (fig. $n^{\circ} 2$ ) 
Chapelle d'aumônier militaire ${ }^{4}$

Figure 1

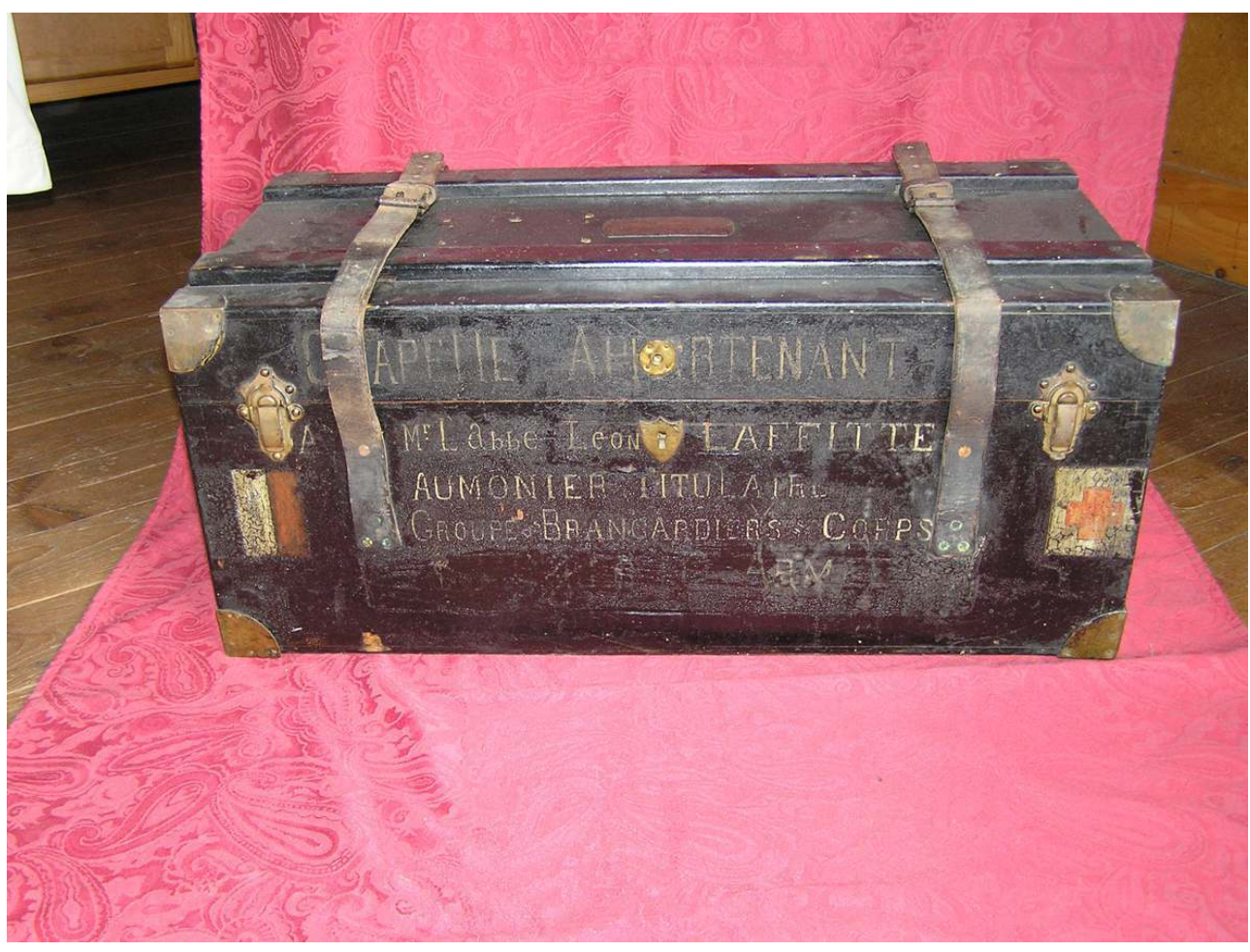

Cantine d'aumônier militaire fermée.

PHOT. C. AlIQUOT. (C) C. ALIQUOT. 
Figure 2

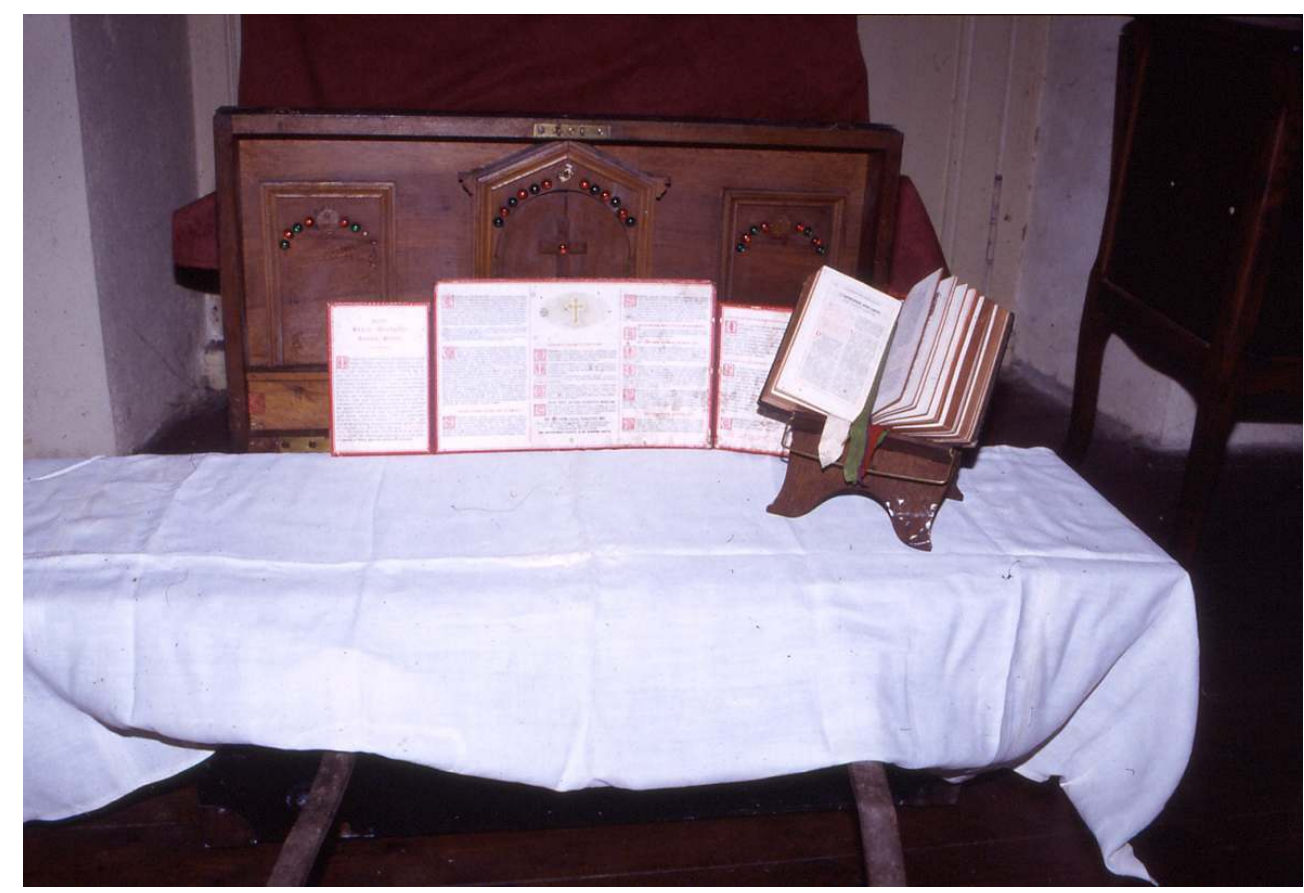

Cantine d'aumônier militaire ouverte, développée en autel.

Phot. C. Aliquot. (c) C. Aliquot.

Il s'agit d'une malle en bois renforcée avec coins en laiton et attaches en cuir, mesurant $70 \mathrm{~cm}$ de longueur, $35 \mathrm{~cm}$ de largeur et $31 \mathrm{~cm}$ de haut. Elle ne contient ni vases sacrés ni vêtements liturgiques. Le nécessaire pour célébrer la messe est conservé : un décor en bois incorporé dans le couvercle de la cantine pour figurer un tabernacle, un support en bois repliable en trois parties pour l'autel, des canons d'autel en carton, un porte missel pliant en bois, un missel Romain daté de 1879, un propre de la Messe en latin sur trois cartons imprimés, un ensemble en aluminium comprenant un plateau ovale et deux burettes, un goupillon en laiton, une pale en soie blanche brodée de feuillages. Figurent également : une statue en plâtre de "Notre-Dame de Lourdes ", une pierre noire gravée en creux à l'envers pour impression, un chemin de croix en carton avec lithographies collées, une petite bourse en damas blanc. (fig. $\left.n^{\circ} 3\right)\left(\right.$ fig. $\left.n^{\circ} 4\right)\left(\right.$ fig. $\left.n^{\circ} 5\right)$ 
Figure 3

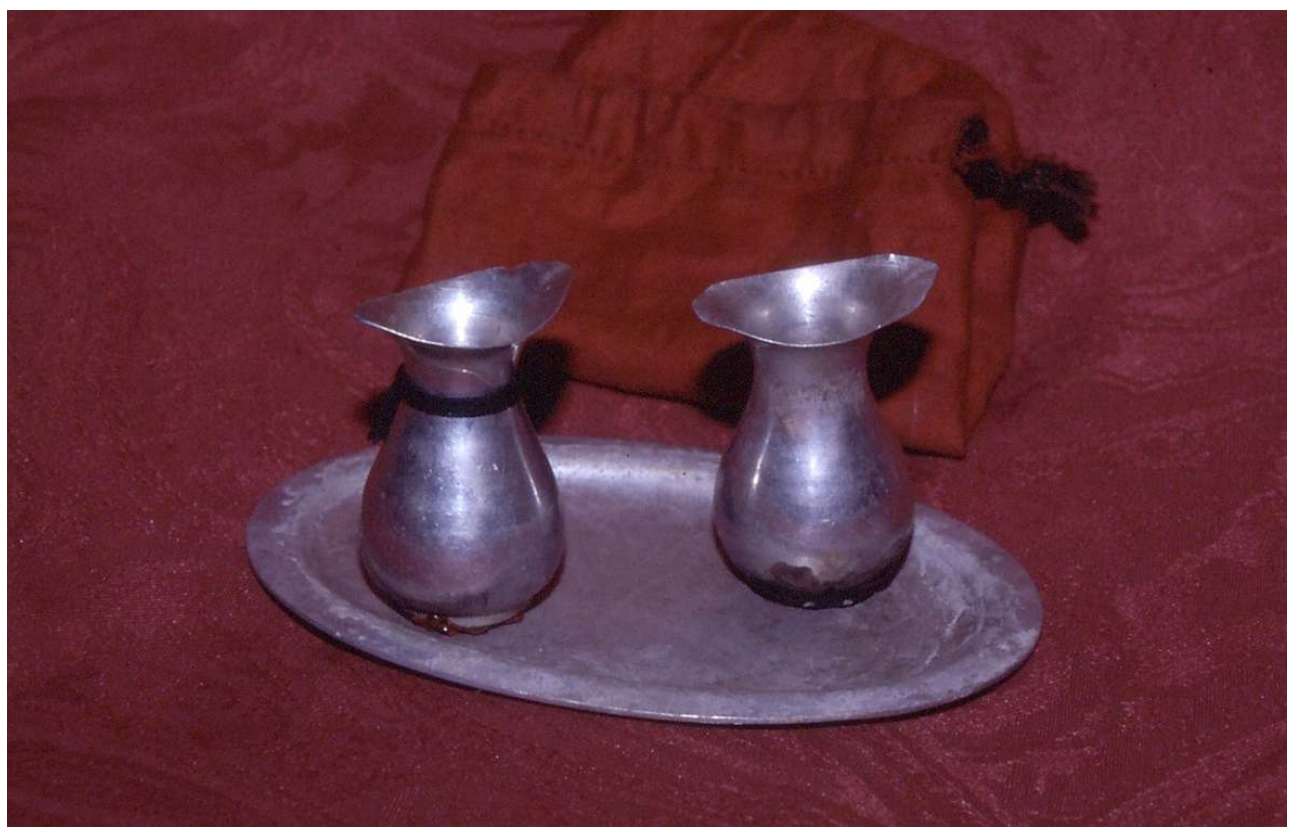

Plateau et burettes.

Phot. C. Aliquot. (c) C. Aliquot.

Figure 4

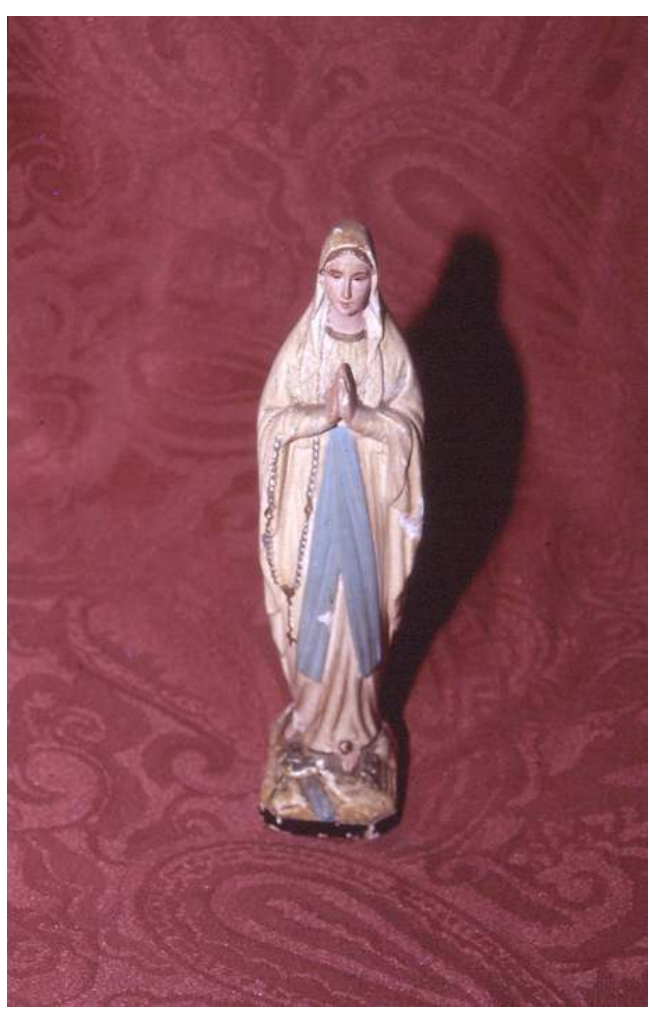

Statuette de Notre Dame de Lourdes. PHOt. C. ALIQUOT. (C) C. AlIQUOT. 
Figure 5

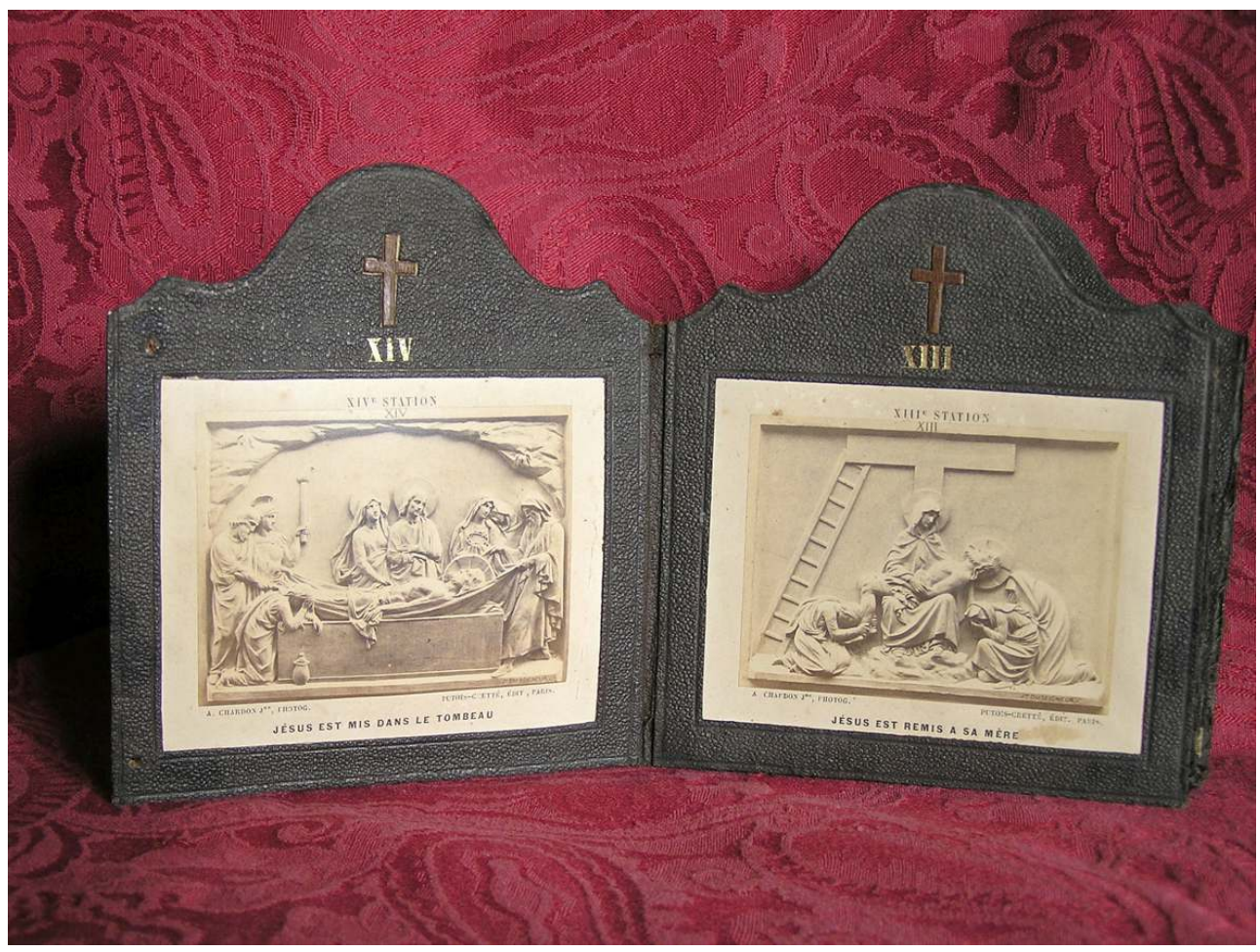

Plaquettes de station de chemin de croix.

PHOt. C. AlIQUOT. (C) C. AlIQUOT.

\section{Valise de prêtre soldat ${ }^{5}$}


Figure 6

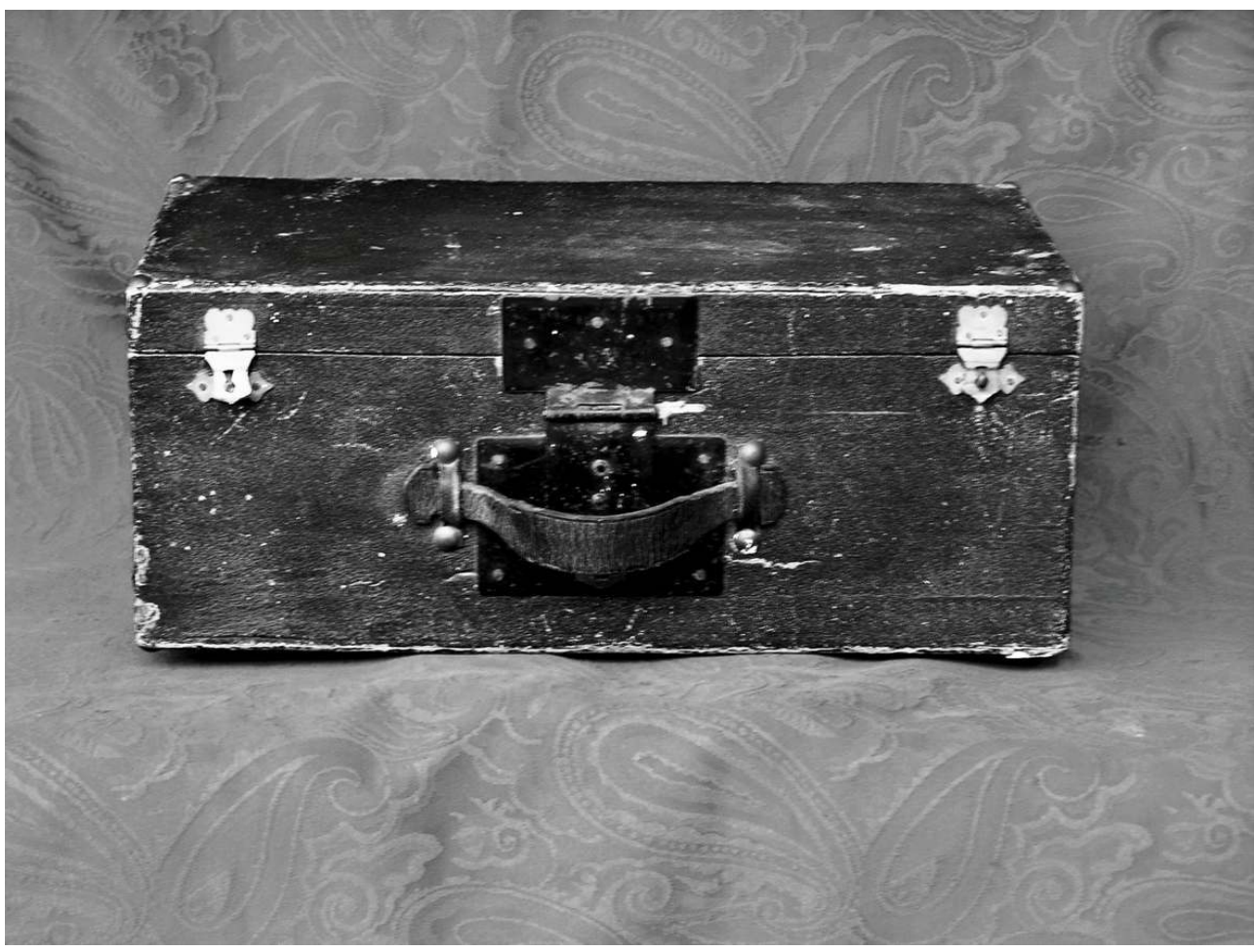

Valise de prêtre soldat fermée.

PHOT. C. ALIQUOT. (C) C. ALIQUOT. 
Figure 7

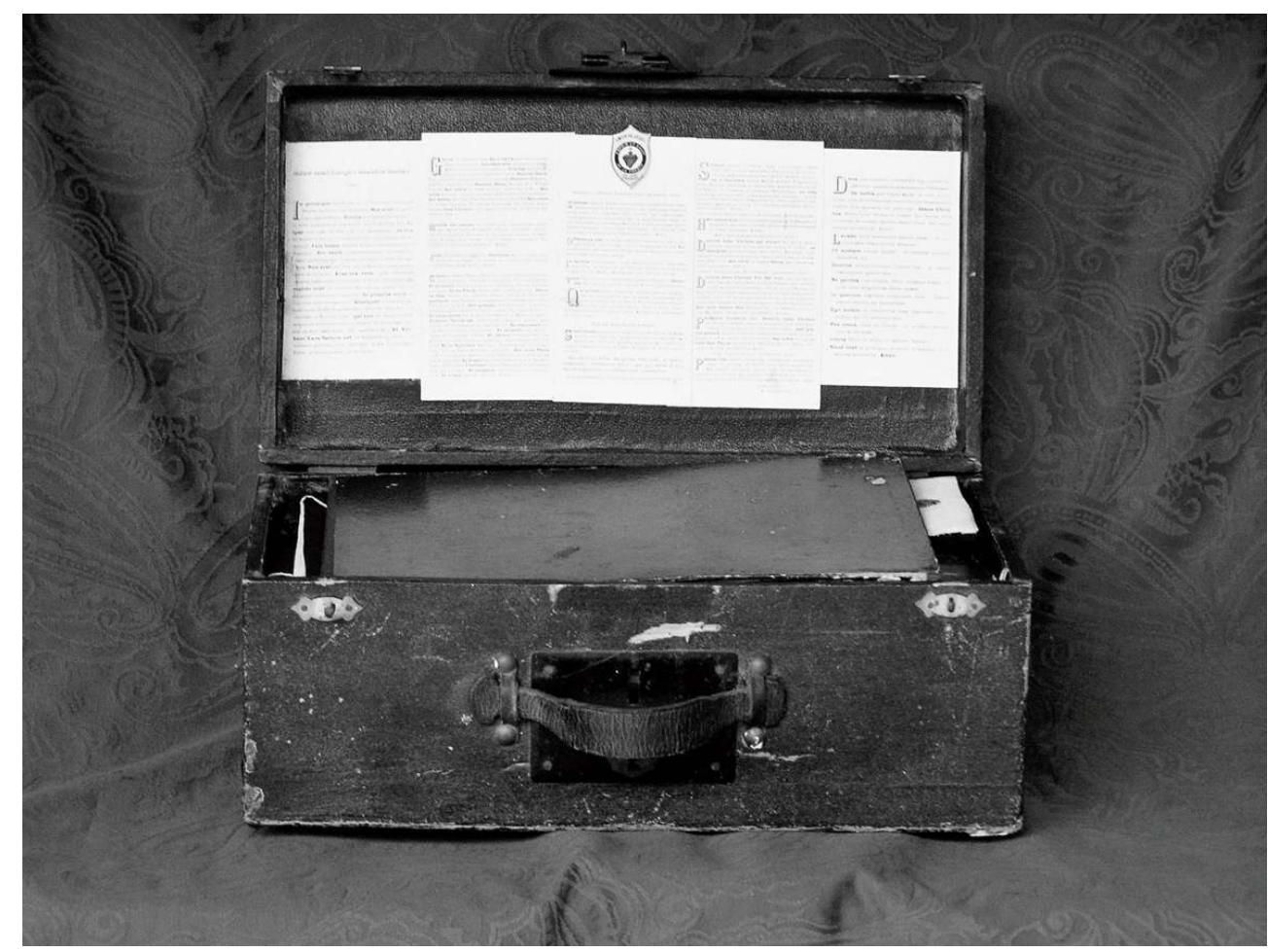

Valise de prêtre soldat ouverte avec canons d'autel collés sur le couvercle.

Phot. C. Aliquot. (c) C. Aliquot.

21 Bien que plus modeste, cette valise en bois recouverte de tissu noir de $38 \mathrm{~cm}$ de long, pour $20 \mathrm{~cm}$ de large et $15,5 \mathrm{~cm}$ de haut est plus complète. Sur le couvercle sont collés les canons d'autel avec le Sacré-Cœur entouré de l'inscription: ESPOIR ET SALUT DE LA FRANCE ${ }^{6}$. À l'intérieur sont déposés trois autres jeux de canons d'autel en carton, deux avec gravures en noir et blanc, un avec décors en couleur, un porte burette ovale en aluminium, mais surtout une aube blanche et un ensemble d'ornements liturgiques réversibles en satin noir et blanc comprenant : une chasuble, une étole, un manipule, une bourse et un voile de calice. Se trouvent également une étole réversible violette et noire en damas, un dessus d'autel en molleton, une nappe d'autel en lin blanc, une pale blanche en lin, un corporal en lin, trois purificatoires ou manuterges, une pochette en satin bleu pour recevoir la pierre d'autel avec un certificat de consécration de la pierre : Cette pierre a été consacrée par Monseigneur CUAZ - Évêque d'Hermopolis - Lyon le 6juillet 1917. (fig. n6) (fig. $\left.\mathbf{n}^{\circ} 7\right)$

Cette valise abrite également un certain nombre d'ouvrages de piété : un missel romain, un guide du servant de messe, un rituel de guerre dédié aux prêtres soldats, aux dames infirmières et aux gardes malades, le manuel religieux du soldat comportant des cantiques français et des chants liturgiques, un livre de prières et de chants pour le temps de la guerre, un livre de prières du soldat catholique (envoyé sur le front à partir de 1916) ${ }^{7}$, un feuillet portant hommage au Père Marie Joseph Cassant - religieux cistercien de l'Abbaye Sainte-Marie du Désert. 
Figure 8

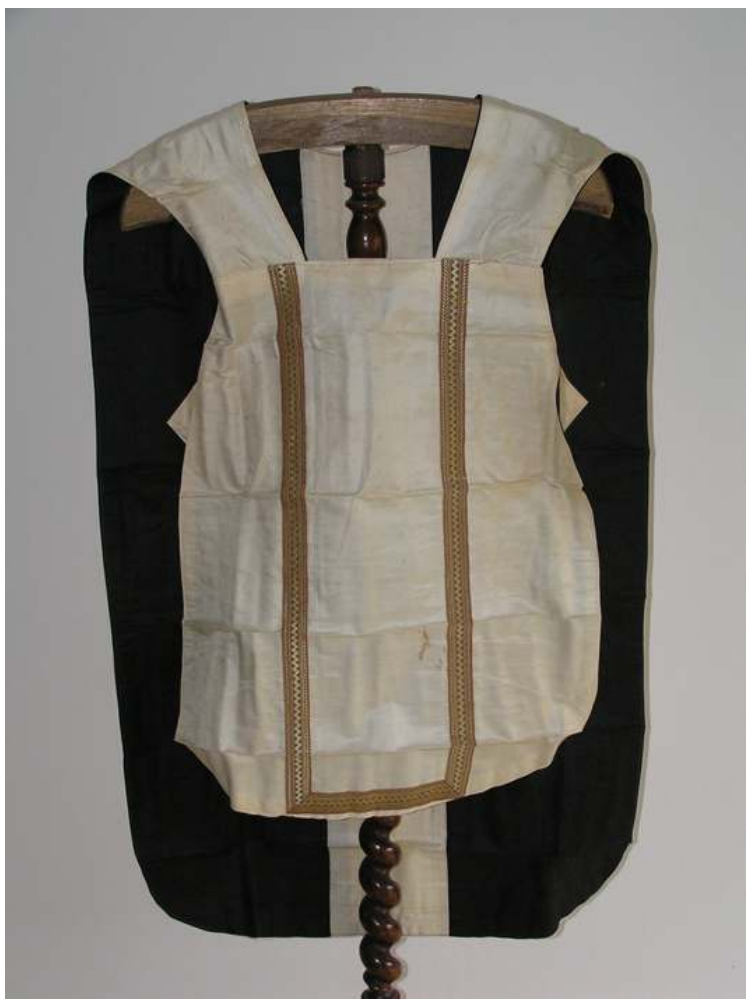

Chasuble réversible blanche et noire. PHOT. C. ALIQUOT. (C) C. ALIQUOT. 
Figure 9

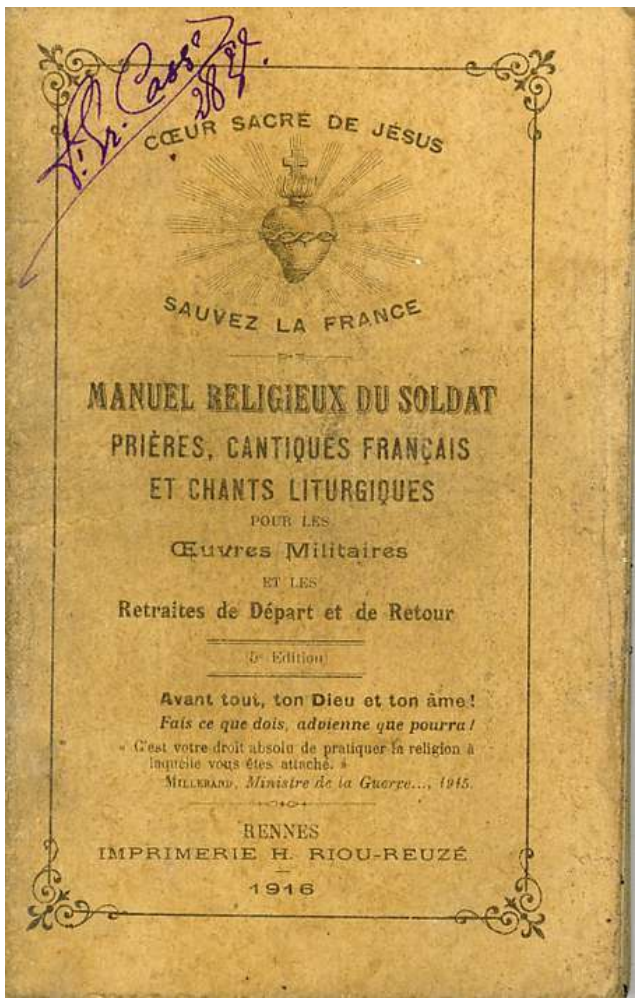

Manuel religieux du soldat.

PHOT. C. ALIQUOT. (C) C. ALIQUOT. 
Figure 10

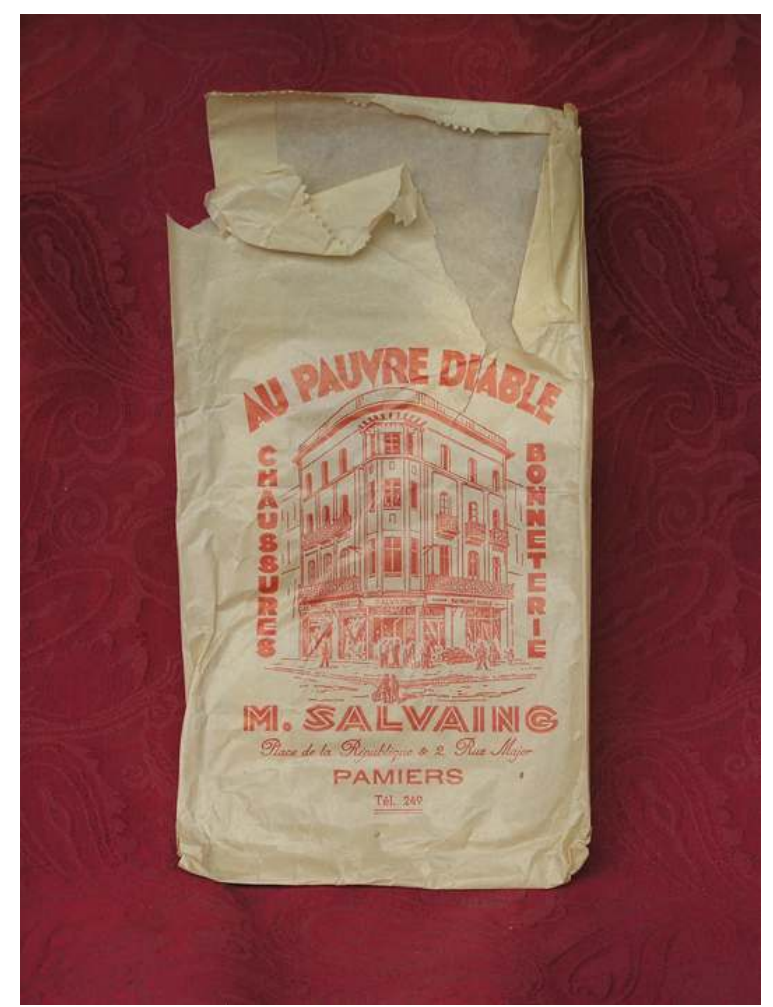

Pochette en papier avec publicité.

PHOT. C. ALIQUOT. (C) C. ALIQUOT.

Nous trouvons également neuf cierges et une pochette en papier dont nous verrons ultérieurement l'intérêt. (fig. $\left.\mathbf{n}^{\circ} \mathbf{8}\right)\left(\right.$ fig. $\left.\mathbf{n}^{\circ} \mathbf{9}\right)\left(\right.$ (fig. $\mathbf{n}^{\circ}{ }^{10}$ )

\section{Propriétaires de ces autels portatifs}

Durant le conflit de 1914/1918, ces autels portatifs étaient affectés nominativement aux prêtres. Nous avons réussi à identifier les deux propriétaires des ensembles qui nous intéressent.

\section{Chapelle d'aumônier militaire}

Pour ce qui est de la cantine d'aumônier militaire, le nom du titulaire était peint sur le couvercle: CHAPELLE APPARTENANT / A Mr L'abbé Léon LAFFITTE /AUMONIER TITULAIRE / GROUPE DES BRANCARDIERS DE CORPS - Secteur 96, et dans un ovale: COMMISSION DE RÉCEPTION / 29.1.13 / PARIS.

Monsieur et Madame Jean Rouzaud demeurant à Foix, donateurs de cette cantine à l'Association diocésaine, eurent l'obligeance de nous fournir nombre de renseignements concernant leur parent ${ }^{8}$; ces informations furent complétées par celles apportées par le Père César Penzo, archiviste du diocèse de Monaco ${ }^{9}$ et par celles reçues des archives du palais de la Principauté. Ces divers éléments conjugués nous ont permis de mieux connaître l'abbé Léon Laffitte. (fig. $\mathbf{n}^{\circ} \mathbf{1 1}$ ) 
Figure 11

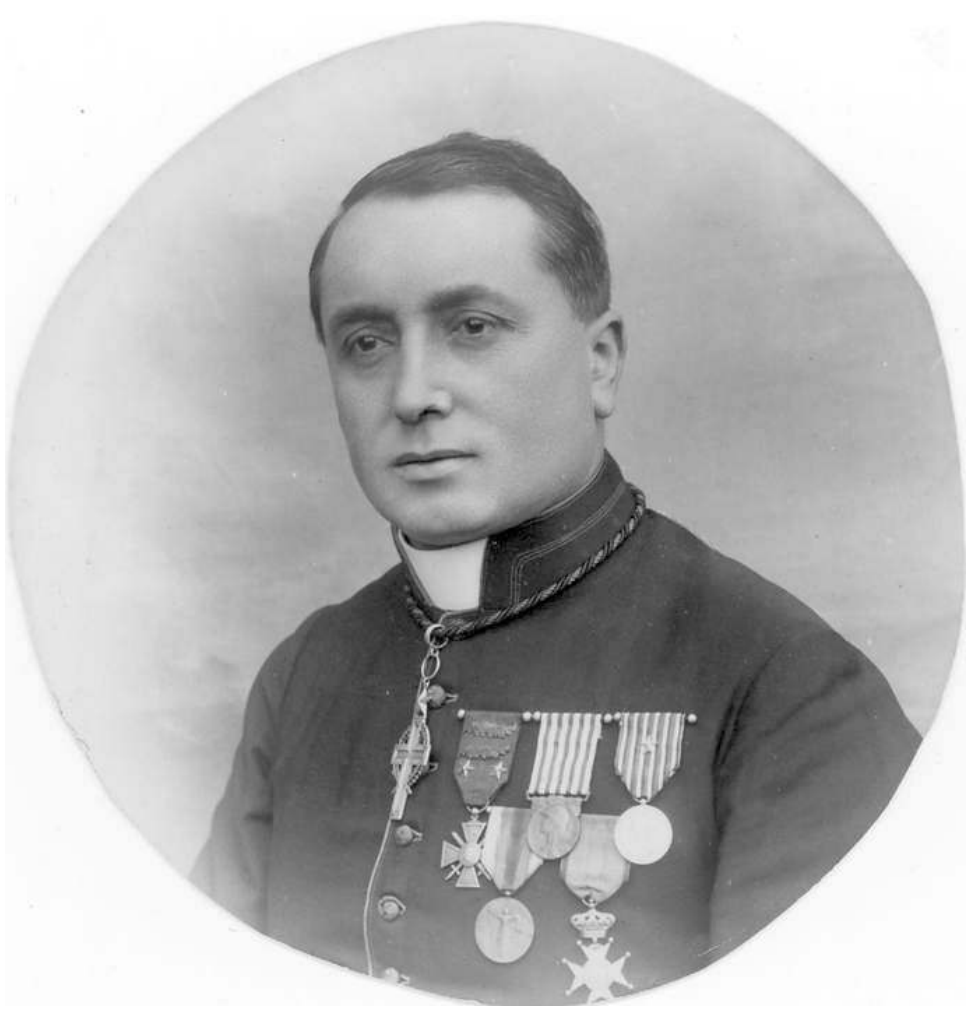

Portrait de Mgr Léon Laffitte.

PHOt. C. AliquOt. (C) C. Aliquot.

Né à Saint-Paul-de-Jarrat, dans le département de l'Ariège, le 6 juin 1885, il fait ses études secondaires au petit séminaire de Pamiers: elles le conduiront à poursuivre la philosophie et la théologie chez les pères Scolopios à Rome. Il est ordonné diacre à Florence le 6 avril 1912, incardiné dans ce diocèse. La prêtrise lui est conférée par le cardinal Mistrangelo, archevêque de Florence, le $1^{\mathrm{er}}$ juin 1912 et il devient secrétaire personnel de ce dernier.

Il s'engage dans l'armée française le 11 novembre 1904 et incorpore le 59e régiment d'infanterie cantonné à Pamiers ; mis en disponibilité le 23 septembre 1905 il est réformé le 7 février 1907. Le 2 août 1914, il s'engage volontaire pour la durée de la guerre et rejoint son affectation comme aumônier au groupe de brancardiers (G.B.C) du $33^{\mathrm{e}}$ corps d'armée ; confirmation de cette titularisation est faite le 5 mai 1915.

En mars 1915, il est présent à la bataille de Verdun, au mois de mars 1915, puis détaché à l'hôpital d'évacuation d'Aubigny-en-Artois le 28 avril. Le 24 juin il est affecté à la $70^{\mathrm{e}}$ division d'infanterie et participe ainsi à la bataille de la Somme. Le 23 juillet 1917, il est envoyé en mission à Vérone et à Venise, après la dixième bataille de l'Isonzo lancée par l'armée italienne contre les troupes austro-hongroises afin d'accéder à Trieste et dont l'issue était restée incertaine ; il est envoyé en mission à Vérone et à Venise, le 23 juillet 1917.

Le $1^{\mathrm{er}}$ août 1918, il est affecté à la $26^{\mathrm{e}}$ division du $13^{\mathrm{e}}$ Corps d'Armée basée à Reims, puis le 3 juin 1919 à la $\mathrm{X}^{\mathrm{e}}$ armée d'occupation en pays rhénan sous la direction de Monseigneur Raimond Pau, évêque de Nice. En 1922, aumônier titulaire auprès des troupes 
d'occupation du territoire de la Sarre et démobilisé le 30 juillet 1930, il reste en Sarre jusqu'en 1935 comme aumônier de la communauté française et cadre de réserve de l'aumônerie.

31 En 1936, il entre comme aumônier de la clinique Notre-Dame à Nice et la même année il est nommé juge d'officialité, puis Vicaire Général du diocèse de Monaco et secrétaire général pour le Congrès Eucharistique international qui devait se tenir à Nice en $1940^{10}$.

Durant la Seconde Guerre mondiale, il est mobilisé le 7 septembre 1939 au Corps Colonial jusqu'au 20 décembre, date à laquelle il est nommé aumônier directeur de la Ve Armée basée à Saverne. Le $1^{\mathrm{er}}$ janvier 1940 il est chargé de la direction de l'Aumônerie catholique auprès du Général de Lattre de Tassigny, au Quartier Général de la Ve Armée; fait prisonnier avec l'État Major le 8 juillet 1940, il s'évade et revient en France. Le 4 juillet 1940 il est démobilisé. Le 25 novembre 1942, il est désigné comme chanoine titulaire de la cathédrale de Monaco ayant rang de vicaire général dans la Principauté ${ }^{11}$. En 1943, il est promu protonotaire apostolique par le pape Pie XII. Il avait été nommé camérier secret du Souverain Pontife Pie XI en 1923.

Les fonctions prestigieuses se succèdent dans la Principauté de Monaco. Le 22 octobre 1943, il est nommé inspecteur des budgets des paroisses ${ }^{12}$. Nous le rencontrons comme inspecteur des écoles primaires le 20 octobre $1945^{13}$, puis le 23 avril 1946, membre du Comité de l'Inspection publique ${ }^{14}$. En 1946, Monseigneur Léon Laffitte est Aumônier du couvent des Augustines de Nice. Le 30 novembre 1950, il prend rang, à titre civil, de Vicaire général honoraire du diocèse de Monaco $^{15}$ et le 8 février 1954 lui est conféré l'honorariat en sa qualité d'ancien Inspecteur des Écoles ${ }^{16}$. Il décède à Saint-Cloud (Hautsde-Seine) le 5 mars 1968 et sera inhumé à Saint-Paul-de-Jarrat trois jours plus tard. Monseigneur Léon Laffitte était titulaire de multiples citations et décorations civiles et militaires.

\section{Valise de prêtre soldat}

Les recherches sur le propriétaire de la valise de prêtre soldat furent plus compliquées. Le premier élément d'information étant l'inscription manuscrite figurant sur la couverture du manuel religieux du soldat: F. Pr. COSSE - 283e . La première déduction voulait qu'un prêtre, du nom de Cosse, ait fait la guerre 1914/1918 dans le $283^{\mathrm{e}}$ régiment d'infanterie. (fig. $\left.n^{\circ} 12\right)$

La tradition française veut que les régiments de réserve portent le même numéro que les régiments d'active augmentés de 200 . Le $283^{\mathrm{e}}$ est donc le régiment de réserve du $83^{\mathrm{e}}$ régiment d'infanterie. En l'occurrence, celui qui nous intéresse étant cantonné à la caserne Jean Pegot à Saint-Gaudens (Haute-Garonne): il est le régiment local des «Commingeois ». 
Figure 12

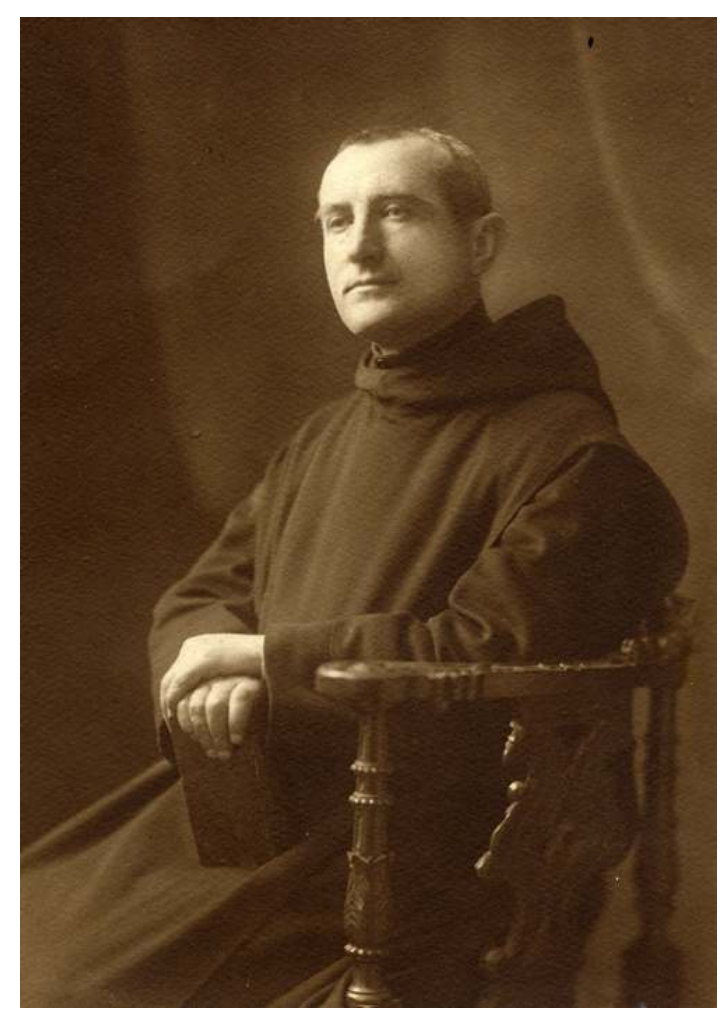

Portrait de Dom Cosse.

PHOT. C. ALIQUOT. (C) C. ALIQUOT.

La seconde recherche fut de voir la relation entre ce prêtre et le feuillet, précédemment évoqué, portant hommage au Père Marie Joseph Cassant - religieux cistercien de l'abbaye Sainte-Marie du Désert. Un échange de correspondance avec le frère Robert, archiviste de ce lieu, nous signala l'inscription sur le cahier de l'hôtellerie du monastère de la présence, en octobre 1908 de Monsieur l'abbé Paul Cosse, curé de Pont-du-Casse, Mercus au diocèse d'Agen $^{17}$.

Nouvelle piste: le diocèse d'Agen. En réponse à un courrier, Monsieur l'Abbé Michel Lazare, archiviste diocésain, nous fait parvenir certains éléments concernant ce prêtre ${ }^{18}$. Né le 13 mars 1870 à Frayssinet Gélat, dans le département du Lot, il fait ses études au séminaire d'Agen (Lot-et-Garonne). Il est ordonné prêtre dans cette ville le $1^{\text {er }}$ mai 1894. Nommé vicaire à Casseneuil le 15 mai 1894, puis dans la même fonction à Saint-Hilaire

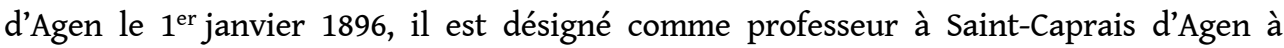
compter du 15 juin 1898. Devenu curé de Merens-et-Serres (Pont-du-Casse) le $1^{\text {er }}$ septembre 1907, il y demeure jusqu'en 1912. Auparavant il avait exprimé le désir d'entrer dans l'Ordre des Bénédictins, aussi obtient-il, cette année-là, l'autorisation diocésaine d'y accéder.

Nouvelle intervention auprès du père abbé de Saint-Wandrille (Seine-Maritime), Dom Jean-Charles Nault, qui nous fait parvenir un extrait de l'histoire de ce monastère dans lequel est mentionné le récit de la vie de Dom Paul Cosse au sein de cette communauté ${ }^{19}$. Ce document nous apprend que dom Paul Cosse reçut l'habit monastique le 18 mars 1912 et la coule de novice le 4 décembre de la même année au château de Dongelberg (Belgique) où le couvent s'était retiré : la communauté bénédictine de Saint-Wandrille 
étant sous le coup d'une expulsion du territoire français suite à la loi de 1901 sur les associations. (fig. $\left.{ }^{\circ}{ }^{13}\right)$ (fig. $\left.n^{\circ} 14\right)$

Figure 13

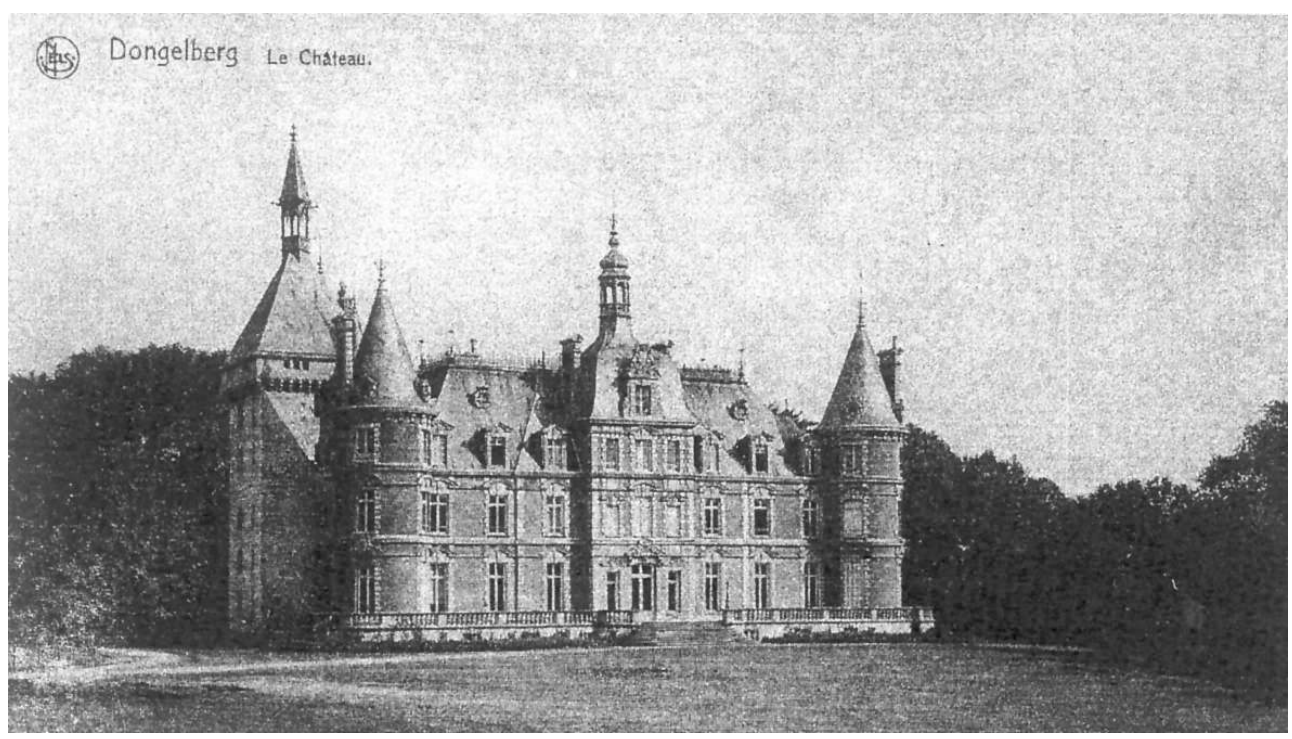

CHÂteAu de dongelberg (BELgiQUe).

REPRO. C. ALIQUOT. (C) C. ALIQUOT.

Figure 14

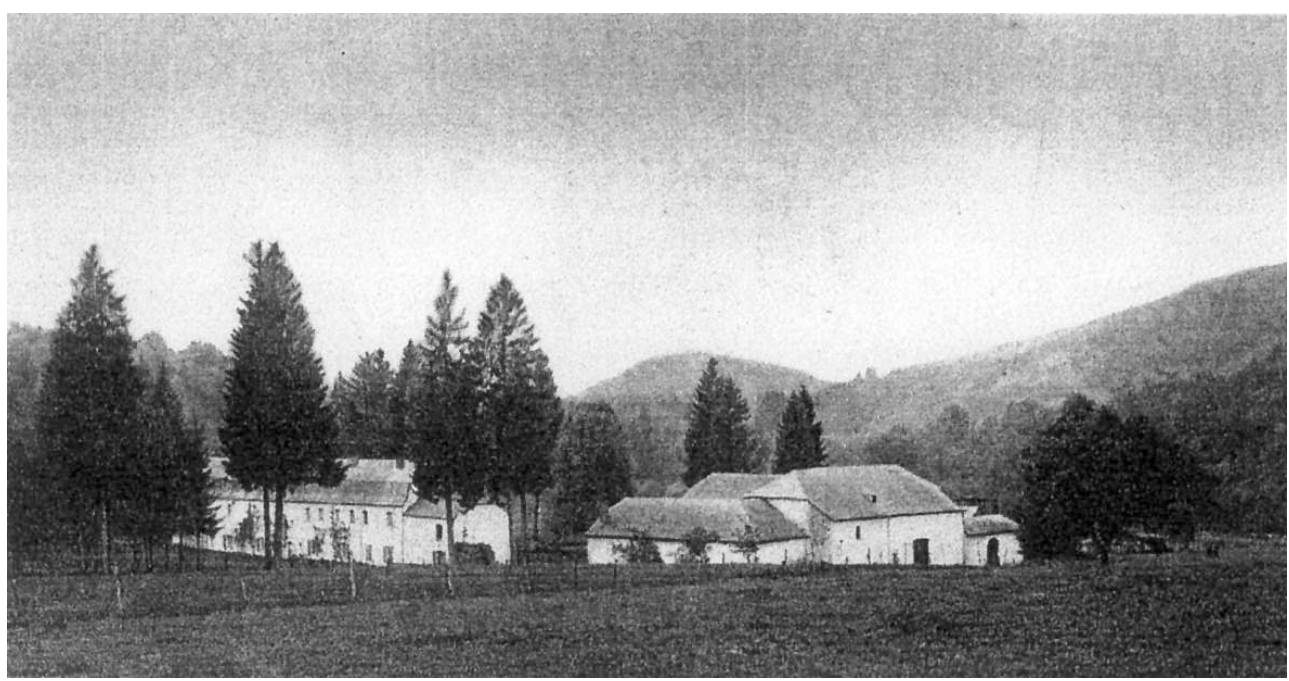

FERME DE CONQUes (BELgIQUe).

REPRO. C. ALIQUOT. (C) C. ALIQUOT.

Le 8 décembre 1913, il fait sa profession monastique à Conques, en Belgique. En août 1914, il est mobilisé à Agen en qualité d'infirmier, demeurant dans ces fonctions tout le temps de la guerre; il participe ainsi à toutes les campagnes du 283e Régiment d'infanterie. Cantonné à Suippes (Marne) le 14 août 1914, dès le 23 il est engagé à Éton (Meuse) dans la région de Verdun. Dans ce combat le $283^{\mathrm{e}}$ perd la moitié de ses effectifs, soit un millier d'hommes sur 2200 dont 23 officiers. En 1916, c'est l'année de Verdun: batailles du 
21 février au 19 décembre; le régiment est à Béthincourt et à Mort-Homme du 6 au 12 mars, puis au Bois des Corbeaux, au nord de Cumières.

41 Le 2 mai 1916, le $283^{\mathrm{e}}$ Régiment d'infanterie reçoit en renfort un bataillon du $259^{\mathrm{e}}$ basé à Foix et à Pamiers. C'est à ce stade que la pochette trouvée dans la valise de prêtre soldat de Paul Cosse présente un intérêt tout particulier. En effet sur celle-ci sont imprimés au recto:

42 AU PAUVRE DIABLE / CHAUSSURES / BONNETERIE / M. SALVAING /

43 Place de la République \& 2 rue Major/ PAMIERS / Tél. 249

44 Ceci conforte notre supposition sur le lien qui unissait cette localité avec le $259^{\mathrm{e}}$ Régiment d'infanterie dont un bataillon a complété le $283^{\mathrm{e}}$ en 1916. Du 17 au 22 août 1916, le $283^{\mathrm{e}}$ intervient toujours près de Verdun aux combats du bois de Vaux-Chapitre et de Fleurysous-Douaumont. D'octobre 1916 à juin 1917, il est en Lorraine : secteur de Fey-en-Haye puis de Limey. Du 16 avril au 24 octobre 1917, il participe également aux combats du Chemin des Dames dans le département de l'Aisne.

Les 30 et 31 mars 1918, il prend part à la seconde bataille de Picardie à Mortemer et Orvillers-Sorel (Oise). Il est ensuite engagé dans la bataille du Matz le 10 juin de cette même année. Le $283^{\mathrm{e}}$ occupe alors le secteur. Au sein de son régiment il participe à la bataille de Serre, dans l'Aisne, qui se déroule du 20 au 30 octobre 1918. À partir de cette date : stabilisation et organisation des positions conquises. Démobilisé, il est de retour à Conques en 1919. Plusieurs charges sont successivement confiées à dom Paul Cosse notamment : maître des convers (1919/1920), préfet des études et de lecteur de théologie morale (1920/1921), bibliothécaire (1921/1924). Il suit la communauté de Saint-Wandrille au Réray (Allier) où elle avait trouvé un nouveau refuge. (fig. $\left.\mathbf{n}^{\circ} 15\right)$ 


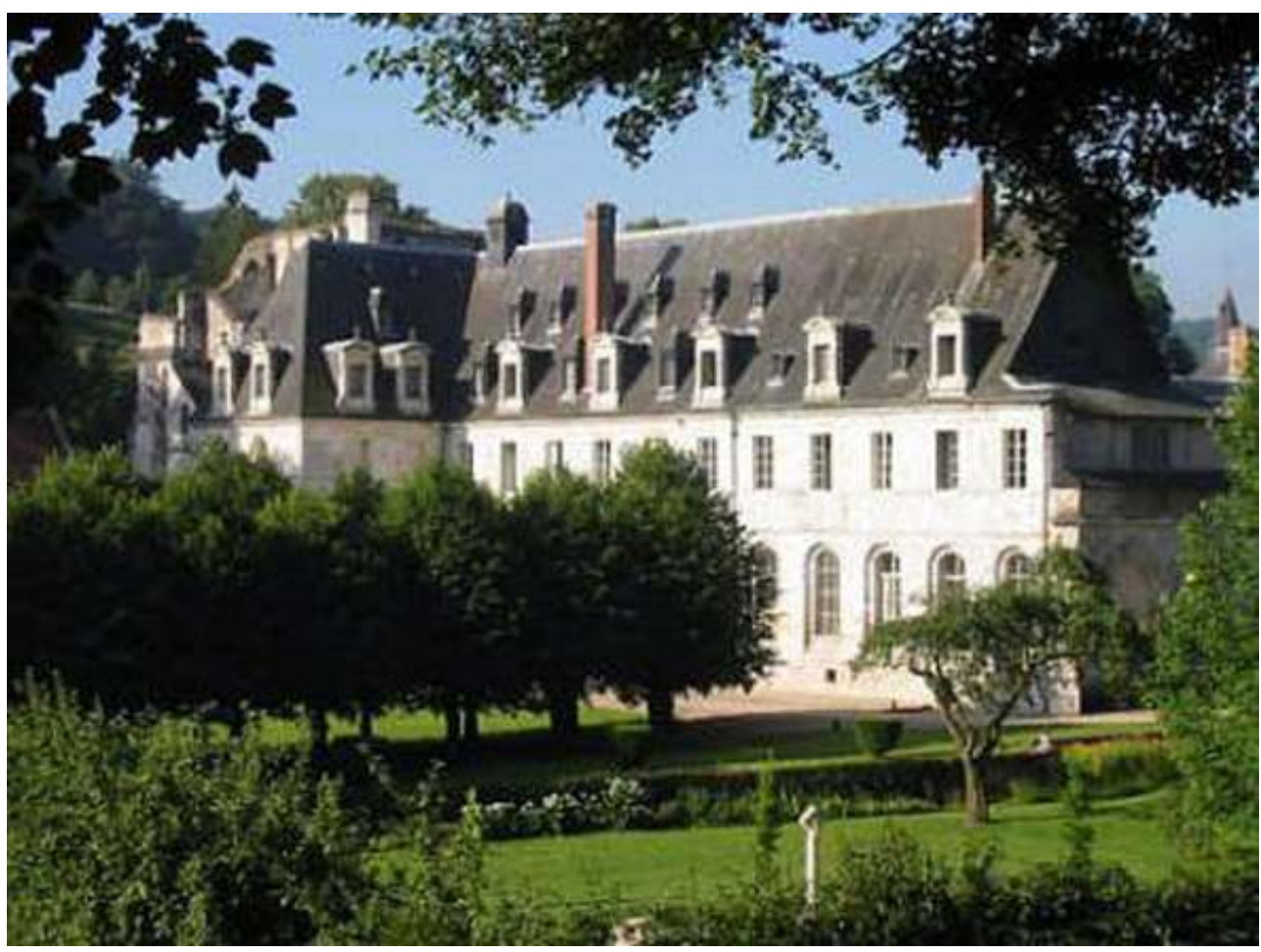

ABBAYE DE SAINT-WANDRILLE (FRANCE).

REPRO. C. ALIQUOT. (C) C. ALIQUOT.

Le 20 juin 1925, suite au décès de dom Vannier, supérieur de la communauté de SaintBenoît-du-Lac, implantée au Canada, il est appelé à remplacer ce dernier dans l'exercice de ses fonctions. Toutefois la rudesse du climat l'oblige à revenir en France en 1928.

De retour à Saint-Wandrille, le 16 novembre 1928, il est choisi comme sous prieur par dom Pierdait et prend en charge l'hôtellerie. Au mois de janvier 1938, une épidémie de grippe particulièrement violente décime la communauté. Dom Cosse est particulièrement affecté par des complications cardiaques. Sa santé rétablie, le 31 décembre 1938, il est désigné par dom Pierdait comme prieur. Il conserve cette fonction sous son successeur : dom Gontard jusqu'au 29 septembre 1940.

La mobilisation et l'avance des armées allemandes ont désorganisé la communauté. Le 9 juin 1940, l'évacuation de l'abbaye se fait en deux étapes: l'une à pied jusqu'à Bourneville, dans l'Eure, l'autre en camion jusqu'à Alençon, dans l'Orne. Dom Cosse réussit avec plusieurs moines à gagner " La Gineste ", près de Duraval, en Lot-et-Garonne, propriété d'un parent. Après l'armistice, ils quittent la «zone libre " pour regagner l'abbaye de Saint-Wandrille. Le 3 octobre 1950, suite à une grave crise d'hémiplégie, son côté droit est paralysé, il éprouve une grande difficulté à s'exprimer. Au soir du 21, dom Cosse plongé dans le coma s'éteint dans la nuit. Il est inhumé le 24 octobre à SaintWandrille.

Certainement cité au titre des combattants, nous n'avons trouvé aucune trace de ses décorations. 


\section{NOTES}

1. - BONIFACE, X. L'Aumônerie française 1914/1962. Paris : Cerf, 2001, p. 68/88, p. 105/153.

2. - Bulletin de l'Éuvre, janvier 1915, p. 3.

3. - LENSION-RIGAU, Éric. Le donjon et le clocher. Paris : Librairie académique Perrin, 2003, p. 340.

4. - Inscrit à l'Inventaire au titre des Monuments historiques « Ariège » le 27 février 2003.

5. - Inscrit à l'Inventaire au titre des Monuments historiques « Ariège » le 11 janvier 2011.

6. - Les préfets avaient interdit le port de cette représentation du Sacré-Cœur de Jésus, mais les «poilus» le portaient souvent cousu à l'intérieur de leur capote ou inséré sous leur casque. Un million et demi d'exemplaires furent distribués. TURBERGUE, Jean-Pierre (dir.). Les 300 jours de Verdun. Triel-sur-Seine : Éditions Italiques, 2006, p. 154.

7. - Bulletin de l'Éuvre, avril 1916, p. 103.

8. - Lettre du 9 octobre 2009 de Monsieur Jean Rouzaud.

9. - Lettre du 21 septembre 2009 du Père César Penzo.

10. - Lettre du 21 septembre 2009 du Père César Penzo.

11. - Ordonnances souveraines $n^{\circ} 2689$ et $n^{\circ} 2690$ du Prince Louis II du 25 novembre 1942.

12. - Ordonnance souveraine $n^{\circ} 2764$ du Prince Louis II du 22 octobre 1943.

13. - Ordonnance souveraine $n^{\circ} 3098$ du Prince Louis II du 20 octobre 1945.

14. - Ordonnance souveraine $n^{\circ} 3213$ du Prince Louis II du 23 avril 1946.

15. - Ordonnance souveraine $n^{\circ} 868$ du Prince Rainier III du 21 décembre 1953.

16. - Ordonnance souveraine $n^{\circ} 897$ du Prince Rainier III du 8 février 1954.

17. - Lettre du 4 novembre 2008.

18. - La Semaine catholique du diocèse d'Agen, 10 novembre 1950, p. 343.

19. - THIRON, dom Joseph. L'abbaye de Saint-Wandrille de Fontenelle, ${ }^{\circ} 1$, Pentecôte 1951, p. 36-37.

\section{AUTEUR}

\section{CLAUDE ALIQUOT}

Conservateur des Antiquités et Objets d'Art de l'Ariège, Docteur en Histoire

claude.aliquot@wanadoo.fr 